\title{
BIODEGRADAÇÃO DE EFLUENTE TÊXTIL POR Pleurotus sajor-caju
}

Hélio Mitoshi Kamida e Lucia Regina Durrant

Departamento de Ciência de Alimentos, Faculdade de Engenharia de Alimentos, Universidade Estadual de Campinas, CP 6121, 13081-970 Campinas - SP

Regina Teresa Rosim Monteiro* e Eduardo Dutra de Armas

Centro de Energia Nuclear na Agricultura, Universidade de São Paulo, CP 96, 13416-000 Piracicaba - SP

Recebido em 27/5/04; aceito em 26/10/04; publicado na web em 28/2/05

\begin{abstract}
BIODEGRADATION OF TEXTILE EFFLUENTS BY Pleurotus sajor-caju. Effluents generated by the textile industry are of environmental concern because of the presence of dyes with complex molecular structure, which confer them recalcitrant characteristics. Indigo is one of the most widely used dyes within the textile sector and studies have suggested that edible fungi may be capable of its biodegradation. A textile effluent was mixed with sugarcane bagasse and inoculated with Pleurotus sajorcaju, the decolorization being evaluated after 14 days, when the process was observed. Enzymatic activities of laccase, peroxidase and manganese peroxidase were determined, the production of these ligninolytic enzymes being evident and a synergism among them being likely in the decolorizing process.
\end{abstract}

Keywords: indigo dye; decolorization; ligninolytic enzymes.

\section{INTRODUÇÃO}

Os processos têxteis são grandes consumidores de água e de corantes sintéticos, geradores de efluentes volumosos e complexos com elevada carga orgânica, aliada ao elevado teor de sais inorgânicos ${ }^{1}$. A grande diversidade e complexidade desses efluentes, aliadas a imposições da legislação que exigem tratamentos eficientes, têm levado ao desenvolvimento de novas tecnologias que buscam o tratamento melhor e mais adequado, considerando custos, tempo e eficiência dos processos existentes na reciclagem e eliminação de toxicidade ${ }^{2,3}$. A preocupação com a estética e qualidade do ambiente atingido por efluentes coloridos leva à busca de alternativas de descoloração, especialmente de corantes têxteis ${ }^{4}$.

Há diversas formas de tratamento para os efluentes têxteis: físicos, químicos e biológicos, sendo que os microrganismos têm sido intensamente estudados com a finalidade de remover compostos tóxicos do ambiente. As pesquisas de degradação de compostos químicos têm mostrado vários microrganismos extremamente versáteis em degradar substâncias recalcitrantes. Os caminhos atuais da biotecnologia indicam fungos basidiomicetos degradadores de lignina, como eficientes na degradação de grande variedade de compostos e de corantes, com alto potencial de ação na recuperação de ambientes contaminados ${ }^{5}$. O problema da remoção da cor em efluentes coloridos tem encorajado a busca de tratamentos biológicos para esta finalidade. Os fungos basidiomicetos denominados "da podridão branca da madeira" têm sido apontados como bons degradadores e eficientes na descoloração ${ }^{6,7}$.

De acordo com Banat et al. ${ }^{8}$, o mecanismo de descoloração de corantes poliméricos por fungos da podridão branca envolve as enzimas lignina peroxidases (LiPs), as manganês peroxidases (MnPs) e lacases. Entretanto, estes fungos diferem na habilidade e capacidade de degradar corantes com base nas diferenças qualitativas e quantitativas dessas enzimas ${ }^{9}$.

Balan e Monteiro ${ }^{10}$ empregaram os basidiomicetos Phellinus gilvus, Phanerochaete chrysosporium, Picnoporus sanguineus e

*e-mail: monteiro@cena.usp.br
Pleurotus ostreatus e constataram a degradação do corante índigo em meio de cultura líquido por estes fungos. Ranzani ${ }^{11}$ selecionou linhagens de Pleurotus capazes de degradar o corante índigo, utilizando meios de cultura líquido e sólido e constatou que o emprego de bagaço de cana misturado com folha de bananeira como substrato oferece condições favoráveis para a degradação deste corante presente em lodo residual, procedente de estação de tratamento de efluente de uma indústria têxtil.

Entretanto, as investigações científicas na área têxtil ainda são escassas. São necessários esforços em encontrar técnicas de bioestimulação e biorremediação para incrementar os conhecimentos, de forma a modificar a realidade que apresenta o ambiente atingido pelos poluentes.

O objetivo deste trabalho foi verificar o potencial de descoloração de efluente têxtil por duas linhagens de Pleurotus sajor-caju e se enzimas ligninolíticas estão envolvidas neste processo.

\section{PARTE EXPERIMENTAL}

\section{Efluente}

Foi utilizado efluente líquido equalizado contendo corante índigo, coletado na caixa de entrada anterior à lagoa de lodo ativado, da estação de tratamento de efluente de uma indústria têxtil da cidade de Americana-SP.

\section{Fungos}

Foram empregados os fungos basidiomicetos comestíveis Pleurotus sajor-caju (CCB 020) (F2), doado pelo Instituto de Botânica de São Paulo e Pleurotus sajor-caju (PSC 94/03) (F6), doado pela Faculdade de Ciências Agronômicas da Universidade Estadual Paulista - Campus de Botucatu, SP.

\section{Condições de cultivo}

Os fungos foram cultivados durante 8 dias em placas de Petri 
contendo MEA (malte, extrato de levedura, ágar). Três discos com $0,5 \mathrm{~cm}$ de diâmetro foram retirados das bordas das colônias e adicionados em cada frasco Erlenmeyer contendo $5 \mathrm{~g}$ de bagaço de cana (desidratado e esterilizado através de radiação gama) e $30 \mathrm{~mL}$ de efluente líquido. Os frascos (em triplicata) foram incubados no escuro, à temperatura de $28^{\circ} \mathrm{C} \pm 2$ por 14 dias.

\section{Atividade enzimática}

No intervalo de 3 dias até o período final de incubação, $30 \mathrm{~mL}$ de água destilada foram adicionados aos frascos e o material homogeneizado, sendo posteriormente filtrado em papel de filtro (Whatman n.1); em seguida este foi centrifugado a $5000 \mathrm{rpm}$ por 10 min sendo o sobrenadante utilizado para as determinações enzimáticas.

As atividades enzimáticas de lacase ${ }^{12}$, manganês peroxidase ${ }^{13}$ e peroxidase ${ }^{12}$ foram determinadas, sendo as reações realizadas em triplicata e as leituras de absorbância efetuadas com auxílio de espectrofotômetro.

\section{Descoloração}

No período final de incubação, o material que ficou retido no papel de filtro, como descrito no item anterior, foi utilizado para avaliação da descoloração por reflectância (medida de cor de objeto opaco) e o procedimento consistiu no uso de um espectrofotômetro (Minolta Chroma Meter CR-200), o qual emite um feixe de luz sobre o material e, em seguida, captura a luz refletida, fornecendo três variáveis representadas pelas letras " $\mathrm{L}$ " (cor variando de preto a branco), "a" (de verde a vermelho) e "b" (de azul a amarelo), em uma escala compreendida entre 0 e 100 para a variável " $L$ " e -60 a +60 , para as demais variáveis.

\section{Análise estatística}

Para análise dos resultados, foi adotado o software "R: A Programming Environment for Data Analysis and Graphics", versão 1.7.1, 2003. Os resultados de reflectância (variáveis L, a e b) dos experimentos de descoloração (dispostos em delineamento inteiramente casualizado) foram submetidos à transformação BoxCox, quando necessário, e à análise de variância (ANOVA) e teste de comparação múltipla de médias de Tukey (pacote multcomp) a $5 \%$ de significância. Foram aplicados os testes de Bartlett para análise de homogeneidade de variância e de Shapiro-Wilk para normalidade dos resíduos. Os experimentos de avaliação de atividade enzimática seguiram um delineamento inteiramente casualizado e foram analisados em um esquema fatorial (dias $\mathrm{x}$ tratamentos). Os resultados, transformados por Box-Cox, quando necessário, foram submetidos à análise de variância (ANOVA) e avaliação de normalidade dos resíduos pelo teste de Shapiro-Wilk. Para comparação múltipla de médias adotou-se o teste de Tukey (função TukeyHSD, pacote base) a nível de 5\% de probabilidade.

\section{RESULTADOS E DISCUSSÃO}

A descoloração total do efluente foi observada aproximadamente aos 14 dias de incubação, através de análise visual dos frascos contendo os fungos (Figura 1), sendo que, após a homogeneização do material com a água, observou-se que o bagaço contendo o efluente sem o tratamento pelos fungos apresentou coloração esverdeada devido ao fato do corante ser azul e misturado com o bagaço que possui coloração amarelada, enquanto que o material tratado pelos fungos apresentou coloração alaranjada, devido à biodegradação do corante presente no efluente (Figura 2). De acordo com a Tabela 1, é possível verificar diferenças nas variáveis "a" e "b" do material tratado com os fungos em relação ao controle, confirmando o fato de que a coloração dos tratamentos diferiu ao final do tempo de incubação, sendo que os tratamentos pelas duas linhagens não diferiram entre si.

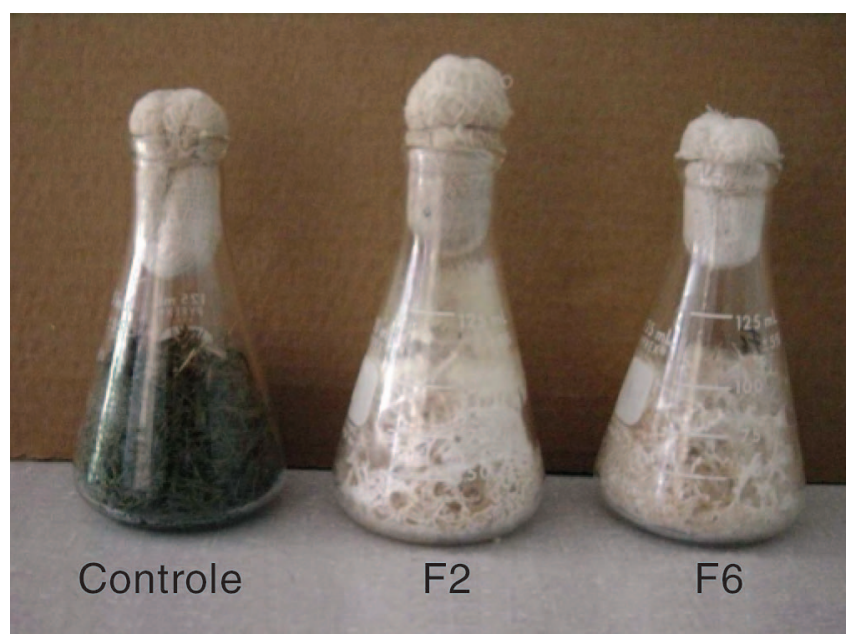

Figura 1. Bagaço de cana misturado com efluente têxtil, inoculados com Pleurotus sajor-caju (F2 eF6), com 14 dias de incubação

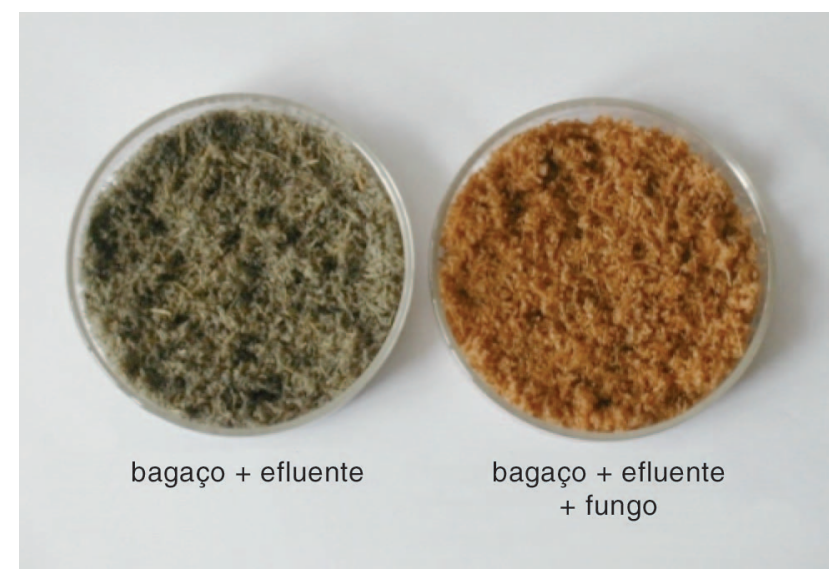

Figura 2. Material homogeneizado a partir de bagaço de cana misturado com efluente têxtil, inoculados com Pleurotus sajor-caju, com 14 dias de incubação

Tabela 1. Análise estatística para os dados de reflectância

\begin{tabular}{lccc}
\hline Tratamento & \multicolumn{3}{c}{ Variáveis } \\
\cline { 2 - 4 } & $\mathrm{L}$ & $\mathrm{a}$ & $\mathrm{b}$ \\
\hline Controle & $36,43 \mathrm{a}$ & $0,80 \mathrm{a}$ & $10,03 \mathrm{a}$ \\
P. sajor-caju CCB 020 & $38,94 \mathrm{a}$ & $10,68 \mathrm{~b}$ & $23,05 \mathrm{~b}$ \\
P. sajor-caju PSC 94/03 & $39,37 \mathrm{a}$ & $10,63 \mathrm{~b}$ & $22,70 \mathrm{~b}$ \\
\hline
\end{tabular}

Médias seguidas por letras minúsculas distintas em cada coluna diferem significativamente a nível de $5 \%$ de probabilidade, pelo teste de Tukey.

Balan e Monteiro ${ }^{10}$ estudaram a descoloração do corante índigo em meio de cultura líquido por quatro espécies de fungos basidiomicetos e verificaram que Pleurotus descoloriu 94\% após 4 dias de incubação. Ranzani ${ }^{11}$ selecionou duas espécies de $P$. sajor- 
caju para degradar lodo têxtil misturado com fonte de lignina e verificou que após 30 dias de incubação, os fungos descoloriram totalmente o material, reduzindo o valor de vários parâmetros, como Demanda Química de Oxigênio (DQO), fenóis e celulose (fibra detergente neutro (FDN) e fibra detergente ácido (FDA).

Em relação à atividade da enzima lacase, pode-se observar o pico de produção aos 9 dias de incubação pelas duas linhagens de fungos na presença do efluente têxtil (Figura 3). Segundo Kerem et $a l .{ }^{14}$, a lacase tanto pode atuar na destoxificação de compostos do substrato como oxidar grupos fenólicos, agindo como enzima inicial na clivagem de cadeias laterais e anéis aromáticos das porções fenólicas da lignina. Outras enzimas de natureza oxidativa, como as álcool veratril oxidases, podem ter um papel importante na degradação da lignina, catalizando a reação do álcool veratril a peróxido de hidrogênio, necessário para atividade de peroxidases ${ }^{15-16}$. De acordo com Kumaran et al. ${ }^{17}$, lacase e manganês peroxidase devem agir em sinergismo. Estudos na descoloração de corantes industriais, inclusive o índigo, enfatizam o papel dessas enzimas produzidas por espécies de Pleurotus $^{18,19}$ na descoloração.

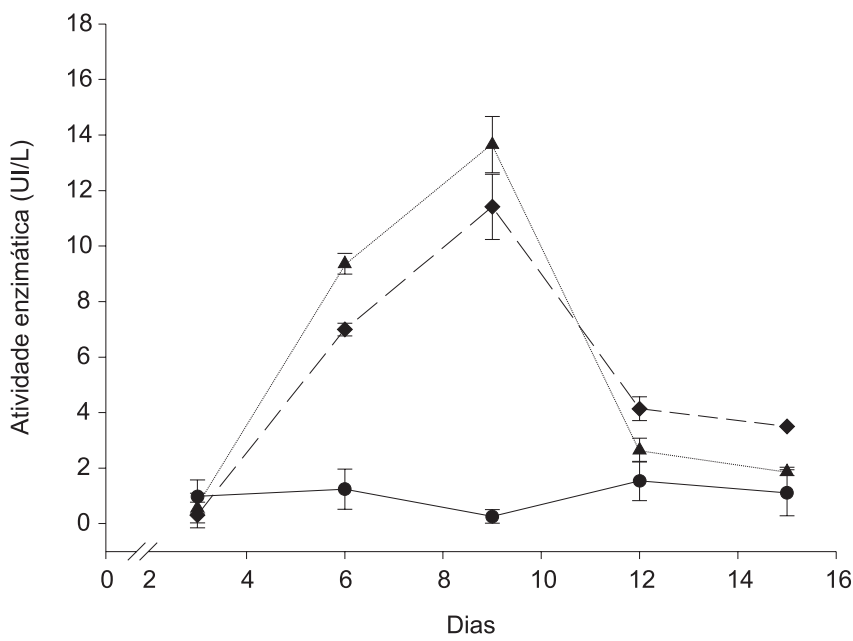

Figura 3. Atividade enzimática de lacase em extratos obtidos de Pleurotus sajor-caju incubados em bagaço de cana contendo efluente têxtil. ( )

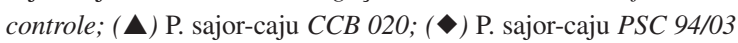

A atividade de peroxidase e a máxima produção também foram detectadas após 9 dias de incubação, comportando-se de forma similar à lacase, em ambas as linhagens testadas (Figura 4). Esta enzima também foi implicada na descoloração in vitro do corante $\mathrm{RBBR}^{20,21}$. Resultados semelhantes foram obtidos com $P$. ostreatus cultivado em bagaço de torta, na produção de óleo de algodão. A produção de lacase e peroxidase ocorreu durante a fase exponencial do fungo, subseqüentemente à ação das enzimas celulolíticas $^{22}$.

A máxima produção de $\mathrm{MnP}$ foi verificada no décimo segundo dia de incubação, não havendo diferença entre as duas linhagens (Figura 5). Na degradação do pireno, em substrato lignocelulósico, a produção de $\mathrm{MnP}$ foi maior entre 20 e 40 dias de incubação, quando a atividade da lacase já havia declinado e foi nesse período que se verificaram as maiores taxas de mineralização desse hidrocarboneto aromático policíclico (HPA) ${ }^{23}$. A correlação entre a degradação de HPAs e o corante "poly R - 478" já havia sido descrita e todos os fungos estudados secretaram as enzimas necessárias para a atividade peroxidativa implicada no processo de degradação/descoloração. A MnP apresentou uma correlação direta e houve a necessidade das oxidases produtoras de peróxido de hidrogênio e peroxidases ${ }^{24}$.

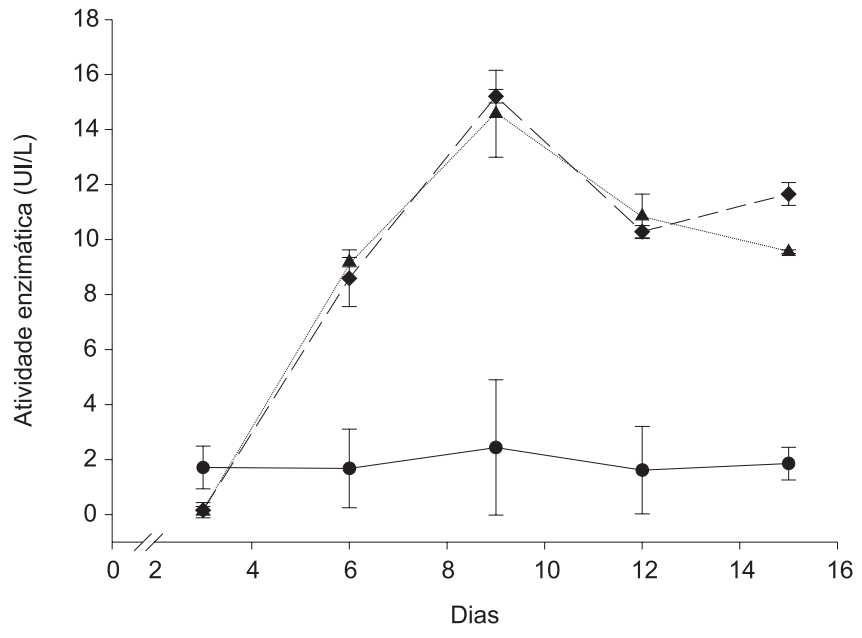

Figura 4. Atividade enzimática de peroxidase em extratos obtidos de Pleurotus sajor-caju incubados em bagaço de cana contendo efluente têxtil ( $\bullet$ ) controle; (ム) P. sajor-caju CCB 020; ( ) P. sajor-caju PSC 94/03

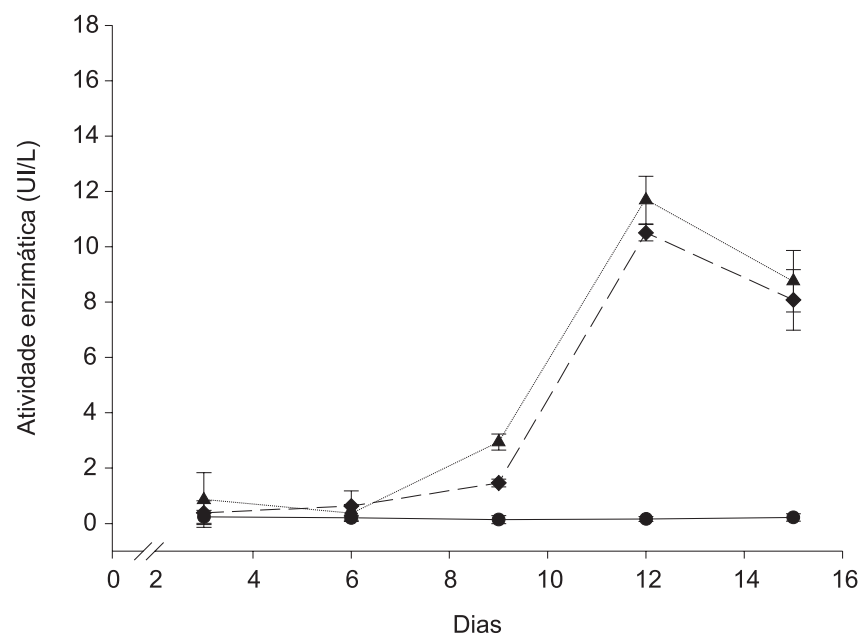

Figura 5. Atividade enzimática de manganês peroxidase em extratos obtidos de Pleurotus sajor-caju incubados em bagaço de cana contendo efluente têxtil. (•) controle; ( $\mathbf{\Delta}$ ) P. sajor-caju CCB 020; ( ) P. sajor-caju PSC 94/03

\section{CONCLUSÕES}

De acordo com os resultados obtidos, verifica-se que existe a produção de enzimas ligninolíticas quando os fungos foram incubados em bagaço de cana contendo efluente têxtil, fato que leva a supor que estas estão envolvidas no processo de descoloração e que têm influência neste processo, pois apresentam atividade em todo o período de incubação estudado.

Os dados apresentados neste trabalho indicam que as duas linhagens de Pleurotus sajor-caju estudadas têm potencial para serem empregadas em bioprocessos para remoção de cor de efluentes têxteis ou no tratamento de resíduos sólidos coloridos, entretanto, existe a necessidade de um melhor entendimento dos mecanismos utilizados por estes fungos para o desenvolvimento de tecnologias para a aplicação destes microrganismos.

\section{AGRADECIMENTOS}

À CAPES pela bolsa de doutorado concedida ao primeiro autor e à FAPESP pelo auxílio financeiro na execução do projeto. 


\section{REFERÊNCIAS}

1. Cegarra, J.; Quim Têxtil 2000, 58, 5.

2. Bumpus, J. A.; Aust, S. D.; Bioassay 1986, 6, 170.

3. Semple, K. T.; Femor, T. R.; Proceedings of the $14^{\text {th }}$ International Congress on the Science and Cultivation of Edible Fungi 1995, 17, 917.

4. Young, L.; Yu, J.; Water Res. 1997, 31, 1187.

5. Barr, D. P.; Aust, S. D.; Environ. Sci. Technol. 1994, 28, 78.

6. Knapp, J. S.; Newby, P. S.; Reece, L. P.; Enzyme Microb. Technol. 1995, 17, 664 .

7. Balan, D. S. L.; Quim. Têxtil 1999, 54, 26.

8. Banat, M. B.; Nigam, P.; Singh, D.; Marchant, R.; Bioresour. Technol. 1996, $58,217$.

9. Vyas, B. R. M.; Molitoris, H. P.; Appl. Environ. Wastewater 1995, 61, 3919.

10. Balan, D. S. L; Monteiro, R. T. R.; J. Biotechnol. 2001, 89, 141.

11. Ranzani, M. R. T. C.; Tese de Doutorado, Universidade Estadual de Campinas, Brasil, 2002.

12. Szklarz, G.; Antibus, R. K.; Sinsabaugh, R. L.; Linkins, A. E.; Mycologia 1984, 81, 234.

13. Kuwahara, M.; Glenn, J. K.; Morgan, M. A.; Gold, M. H.; FEBS Lett. 1984, 169, 247.
14. Kerem, Z.; Friesem, D.; Hadar, Y.; Appl. Environ. Microbiol. 1992, 58, 1121.

15. Waldner, R.; Leisola, M. S. A.; Fichter, A.; Appl. Microbiol. Biotechnol. $1988,29,400$

16. Guillén, F.; Martínez, A. T.; Martínez, M. J.; Evans, C. S.; Appl. Microbiol. Biotechnol. 1994, 41, 465.

17. Kumaran. S.; Sastry, C. A.; Vikineswary, S.; World J. Microbiol. Biotechnol. $1997,13,43$.

18. Rodriguez, E.; Pickard, M. A.; Vasquez-Duhal, T. R.; Curr. Microbiol. 1999, $38,27$.

19. Swamy, J.; Ramsay, J. A.; Appl. Microbiol. Biotechnol. 1999, 51, 391.

20. Kim, B. S.; Ryu, S. J.; Shin, K. S.; J. Microbiol. 1996, 34, 101.

21. Shin, K.; Kim, C.; Biotechnol. Lett. 1998, 20, 569.

22. Akhmedova, Z. R.; Appl. Biochem. Microbiol. 1994, 30, 32.

23. Lang, E.; Nerud, F.; Novotná, E.; Zadrazil, F.; Martens, R.; Folia Microbiol. 1996, $41,489$.

24. Field, J. A.; Jong, E.; Feijoo-Costa, G.; Bont, J. A. M.; Trends Biotechnol. $1993,11,44$. 